$R M x A C, \mathbf{5 3}, 155-157$ (2021)

(c) 2021: Instituto de Astronomía, Universidad Nacional Autónoma de México

https://doi.org/10.22201/ia.14052059p.2021.53.31

\title{
ROBOTIC TELESCOPES FOR UNIVERSITY STUDENTS AND FACULTY
}

\author{
E. Ansbro ${ }^{1}$ and S. G. Hipólito ${ }^{1}$
}

RESUMEN

Las nuevas instalaciones de observatorios de Space Exploration Limited (SEL) en España apoyarán una amplia gama de actividades educativas y profesionales, desde proyectos de nivel inicial hasta innovadoras investigaciones profesionales y de posgrado. Los telescopios robóticos y la instrumentación sofisticada pueden ayudar a diseñar un plan de estudios de astronomía, así como a llevar a cabo proyectos individuales de investigación o aprendizaje a corto o largo plazo. Las instalaciones del observatorio de SEL apoyan al profesorado al proporcionar un enfoque fácil, práctico y rentable en el que no hay necesidad de desarrollar, comprar o mantener equipos astronómicos. Debido a la amplia gama de instrumentación, se pueden realizar investigaciones para sentar las bases y aumentar las posibilidades de obtener tiempo en los telescopios más grandes. Los telescopios robóticos se pueden integrar con éxito en la educación al evitar los desafíos descubiertos por la investigación mundial en esta área.

\section{ABSTRACT}

Space Exploration Limited (SEL) new observatory facilities in Spain will support a diverse range of educational and professional activities, from entry-level projects to innovative graduate and professional research. Robotic telescopes and sophisticated instrumentation can aid in designing an astronomy curriculum as well as carrying out individual short-term or long-term research or learning projects. SEL's observatory facilities support faculty by providing an easy, practical and cost-effective approach in which there is no need to develop, purchase or maintain astronomical equipment. Because of the extensive range of instrumentation, research can be carried out to lay the foundation to increase the chances of getting time on the largest telescopes. Robotic telescopes can be integrated successfully into education by avoiding the challenges uncovered by worldwide research into this area.

Key Words: education — telescopes

\section{INTRODUCTION}

New facilities in Spain enable professors, students, and teachers of astronomy and astrophysics to schedule time on research-grade fully robotic telescopes on a commercial first-come, first-served basis. The site location is at 1500 metres (5000 feet) altitude in Monte de las Animas Starlight Reserve Area, Jaén Province, Andalucía and has excellent seeing conditions. The first telescopes will be operational in 2020. As the telescopes are robotic, no travel is necessary. Visits can be arranged; independent selfcatering accommodation is available nearby for up to 30 persons with conference room, communal areas and swimming pool. While this paper focuses on university professors, students and post-graduates, secondary and primary students with a motivated teacher can carry out suitable projects and original research as well.

\footnotetext{
${ }^{1}$ Space Exploration Ltd, Kingsland, Boyle, County Roscommon, Ireland.
}

\section{SUPPORTING STUDENTS AND FACULTY}

The Space Exploration Limited (SEL) observatory facilities will support a diverse range of educational and professional activities, from entry-level projects to innovative graduate and professional research. Robotic telescopes and instrumentation aid in designing an astronomy curriculum as well as carrying out individual short-term or long-term research or learning projects. Fitzgerald (2018) For example, faculty can develop their own exercises or research projects in a cooperative format, in which students work in teams of three to solve research problems using inquiry-based methods. Gomez (2017) Where extended discussion or more involved interaction with students or faculty is desired, Space Exploration can provide suggestions or "packages" for entry-level or more advanced projects on a case-bycase basis. Fitzgerald (2014)

\subsection{Student Research}

Examples of research projects focused on the Solar System include determining the rotational periods of asteroids where follow-up observations are 
needed. Astrophysics topics might include timing observations of eclipsing binary stars, photometry of newly-discovered supernovae, or carrying out spectroscopy of emission-line stars using a highresolution spectrograph. The observatory can help to select the right telescope, camera and instrument for these undertakings. Any level of confidence or experience in faculty members is welcome and the user interface is designed in a way to be simple to use for all experience levels.

A particularly appealing opportunity exists for students of any level of experience to carry out genuine new research, producing results of use to the broader scientific community and with potential for publication. For example, asteroid photometry can be submitted to the Minor Planet Bulletin for publication. Fitzgerald (2015)

A popular topic for astronomy students is exoplanets. Students could experimentally determine the effect of an exoplanet passing in front of its host star. Then, each group could examine stars showing signs of exoplanet transits. From the images of the star, each group can extract a light curve. From this light curve and the properties of the exoplanet can be estimated. If desired, SEL can recommend appropriate follow-up observations and post-analysis to the faculty; for example, a time-delay series of images of a known exoplanetary system during a transit. Using the transit model, the images of the star, and the relations for exoplanets properties, the student could determine the radius, orbital period, and distance from the parent star of the exoplanet. Experiments can be designed to give students practical experience of key principles important for astronomy and astrophysics, as well as more ambitious research.

\subsection{Planning}

When planning an observing project, an authorised faculty member or student uses the online interface to select the observing parameters they require. This might include a specific telescope/camera combination, filters, spectrograph, polarimeter, exposure time and other parameters. A specific observing time can be requested. Astronomical data will be delivered by ftp immediately following the scheduled observation.

\subsection{Familiarisation, Research, and "Prototyping"}

Getting time on the world's largest telescopes is highly competitive. Faculty members and students alike can benefit by carrying out preliminary research to test their hypotheses on SEL's mid-sized telescopes using advanced instrumentation such as spectrograph, polarimeter or narrow-band filters. This initial research will lay the foundation to increase the chances of getting time on the world's largest telescopes, should the research topic require this. Some projects could thus be considered as a way to "prototype" a new research process.

Space Exploration's observatory facilities support faculty by providing an easy, practical and costeffective approach in which there is no need to develop, purchase or maintain astronomical equipment. This saves time and money. There are facilities at the observatory for visitors when arranged in advance. The online presence has a clear user interface to schedule observations with ease. Best of all, there is no need to justify research objectives or wait for committee decisions. The facilities operate on a simple basis of first come, first served. Depending on the requested target, scheduling can be general or precise. In the case of bad weather or other issues, observations can be rescheduled.

Global research into the use of telescopes in education revealed that a common impediment was the requirement for excessive bureaucratic procedures (lengthy applications, etc.) Another common problem was that in some cases, teachers without professional astronomy experience were not satisfied with an automated process that only provided images but no further support. Gomez (2017) SEL is committed to avoiding these potential pitfalls by ensuring a simple, non-competitive process to get telescope time, and by offering packages of additional support services for teachers who desire them. This could facilitate suitable project definition, choice of instrumentation, data analysis options, and eventual publication. Selecting telescopes and instrumentation depends on the project. Space Exploration's telescopes and instrumentation include:

Telescopes:

$0.4 \mathrm{~m}$ (16 inch) SCT @ f/5 for UBVRI imaging

$0.4 \mathrm{~m}$ (16 inch) Direct Imager @ f/ 3.5 for wide field imaging (LRGBHa)

$0.6 \mathrm{~m}$ ( 24 inch) Cassegrain @ f/18 for polarimetry

$0.6 \mathrm{~m}$ (24 inch) RC @ f/8 for narrow-band imaging and spectroscopy

$0.9 \mathrm{~m}$ (36 inch) Astrograph @ f/4 for narrow band imaging

\section{REFERENCES}

Fitzgerald, M. J., James, C. R., Buxner, C. R., \& White, S. 2018, Robotic Telescopes, Student Research and 
Education (RTSRE) Proceedings Conference Proceedings, San Diego, California, USA, Jun 18-21, 2017, Vol. 1, No. 1

Fitzgerald, M. T., Hollow, R., Rebull, L. M., Danaia, L.,
\& McKinnon, D. H. 2014, PASA, 31, 37

Fitzgerald, M. T., McKinnon, D. H., \& Danaia, L. 2015, JAESE, 24, 747

Gomez, E. L. \& Fitzgerald, M. T. 2017, AstRv, 13, 28 